\title{
Health Problems among Disciplines at a Regional University in Southern Thailand: A Descriptive Study
}

\author{
Supakorn Sripaew, M.D., Chanon Kongkamol, M.D.
}

Department of Family Medicine and Preventive Medicine, Prince of Songkla University, Hat Yai, Songkhla 90110, Thailand.

Received 7 May 2019 • Revised 28 October 2019 • Accepted 13 January 2020 • Published online 12 March 2020

\begin{abstract}
:
Objective: To determine incidence of various health problems among Prince of Songkla University (PSU) students, and its distribution among disciplines.
\end{abstract}

Material and Methods: A Retrospective study, collecting secondary de-identified hospital records of 45,093 PSU students, over the 6-year period of study; from $1^{\text {st }}$, January 2012 to $31^{\text {st }}$, December 2017.

Results: According to data from 45,093 students, there were 8 groups of influential health problems that were shared in approximately 80 percent of all diagnoses. Acute upper respiratory tract infections played the greatest incidence among all disease groups. Apart from that, common health issues found in adolescence consisted of; common skin diseases, traffic accidents, and diseases of the digestive system also played a part as the most common problems. Even if the traffic accidents rate seemed to be overlooked by its number, its incidence rate was 17.41 per 1,000, which was above the provincial rate as well as country rate. Disciplines in the medical group and freshmen group were the highest of patients having most of the common problems. Each health problem incidence rate, which varied within the university campus, seemed to be from the difference of disease burden among disciplines; rather than the ease of facility accessibility. Conclusion: The collegians experienced wide ranges of common health problems, which were predominated in adolescents, and adults. Medical sciences students and freshmen were the highest number of patients for almost all health issues. Overall, health problems among the collegians probably varied in the campus due to specific characteristics in each disciplines, and differed as to the different context in other universities.

Keywords: health problems, discipline, regional university

Contact: Supakorn Sripaew, M.D.

Department of Family Medicine and Preventive Medicine,

Prince of Songkla University, Hat Yai, Songkhla 90110, Thailand.

E-mail: citrus_hystrix@hotmail.com

(c) 2020 JHSMR. Hosting by Prince of Songkla University. All rights reserved.

This is an open access article under the CC BY-NC-ND license

(http://www.jhsmr.org/index.php/jhsmr/about/editorialPolicies\#openAccessPolicy).
J Health Sci Med Res 2020;38(2):103-114 doi: $10.31584 /$ jhsmr.2020729 www.jhsmr.org 


\section{Introduction}

College students could be a key population for the country's growth and success in the future. Universities are places that combine the aspects of both school and workplace, in terms of a unique compilation of: social, environmental, behavioral, political, economic, legal, philosophical and cultural issues. Apart from the variety, some of them are more vulnerable to exposed health risks than others, for instance; healthcare-related discipline students have a unique demand for health services as they are likely to be exposed to blood and patient tissue. ${ }^{1}$ As adolescences make up a majority of the university student population, various disease profiles found in the collegian have resembled the illnesses of this age group. ${ }^{1}$ Recently, increasing global concerns about student health issues, especially mental health, have been reflected among different publications. ${ }^{2}$ On the other hand, traffic injuries also play out as the highest disability-adjusted life years (DALYs) lost in adolescent men, whereas iron deficiency anemia has been contributed to be the highest DALYS in female adolescents. However, these health issues are diverse over different countries. When focusing on low to middle income countries, in South East Asia, road traffic injuries coupled with iron deficiency anemia contributed as the most common. ${ }^{3}$ Turner conducted surveillance during 2011-2014, in 23 universities from the United States (US) ${ }^{4}$, and this study found that nearly half of the students sought health care from their prevention-related services. Previous cross-sectional studies revealed that overall prevalence of traumatic injuries in college students was $28.7 \%$, in which almost of them were sport-related with only $14.0 \%$ being traffic-related. ${ }^{5}$ With a focus on the situation in low to middle incomes, a study reported that unintended injury prevalence in the last 12 months was $14.1 \%{ }^{6}$ In Thailand, there was a prevalence study regarding psychiatric disorders of Khon Kaen University students in 1989, which revealed overall prevalence of mental problems as 4.6 per 1,000 individuals a year. ${ }^{7}$ In fact, however, road traffic injuries have been still playing out as a major cause of death as well as disabilities in Thailand. ${ }^{8}$ There is a little evidence, in Thailand and another country, focusing on the overall health problems among disciplines. This study was conducted to define the incidence of various health problems among the collegians along with their characteristics, including year of study and disciplines, which could be beneficial in terms of understanding students' features and establishing future health policies.

\section{Material and Methods \\ Setting}

Prince of Songkla University (PSU), Hat Yai campus, is a regional university in southern, Thailand, established in 1982. Currently, the university has admitted more than ten thousands students per year, and applies to 21 disciplines. Songklanagarind Hospital is a university hospital, belonging to the Faculty of Medicine, and as such is a hospital containing a medical school, residency training along with it being a referral center for the southern region. The Division of Health Promotion within the hospital has also coordinated with the student health center in terms of shared information gathering along with providing health preventive programs for the students.

\section{Data}

We retrieved de-identified data of the university students, from the Division of Health Promotion. This research was approved by the Human Research Ethics Committee (HREC) of the Faculty of Medicine, PSU: reference number REC 61-284-9-4. In total 45,903 participants enrolled in this study from Bachelor degree status and from college students attending PSU, during 2012-2017, which is considered as approximately $90.0 \%$ of the student population. Health care facilities included in this study, included; all outpatient clinics, for example: the 
primary care, student health center, internal medicine, pediatric, psychiatric, and obstetrics and gynecology and emergency room of the hospital. Students visiting the center, were diagnosed and recorded by International Statistical Classification of Disease and Related Health Problems version 10 (ICD-10).

\section{Variables}

Variables included were: the ICD-10 code and baseline student information, including; age, gender, and discipline. The codes were categorized into 22 groups of the ICD-10 chapter. The disciplines were grouped into 4 groups, including: medical sciences (medicine, dentistry, pharmaceutical science, nurse, Thai traditional medicine, medical technology, and veterinary science), natural sciences (science and engineer), social sciences (arts, economy, law, and management science) and others, according to the Ministry of the University Affairs, in terms of learning style and to protect confidentiality.

\section{Statistical analysis}

Data management and analysis were conducted using R version 3.4.3 and Microsoft Excel $2010^{\circledR}$. Crude incidence ratio was computed for a 6-year cumulative incidence rate (2012-2017) in each group, considering follow up issues, for instance; diagnosis among follow up visits of neoplasm and repeated diagnosis among any disorder with chronic in the name would be considered as a chronic disease and was only counted once, even if recorded multiple times by the same ICD-10 code. Incidence of the diseases, and their group were computed by divided number of cases by those who studied during the study period (6 years). The sex-standardized incidence rates, within each group of discipline, were compared to those of the general students, regarding the standardized rate ratio (SRR) of incidence rate. Top 10 diagnoses, together with influential, adolescent problems, were picked for incidence rates, influential university health problem illustration. Groups of diagnoses with a trend of 80 percent, or more of contributions to the incidence rates (Pareto's analysis) ${ }^{9}$ were also considered (in supplemental document 1).

\section{Results}

Among the 45,903 students enrolled, 21,939 of them utilized university health services during 2012-2017, with approximately 125,000 visits. Primary Care Unit, and the student health center shared more than a half of these visits. Two thirds of the population were female. Age of the students was mainly distributed (>95.0\%) at an interval of 16-24 years, with half of them having experienced a visit to the hospital. We found that, the mean age in the 2 groups were; 20.9 and 19.0 years. According to the study grouping protocol, there were 4 groups of students, with more than $50.0 \%$ from natural sciences and social sciences (8,743 from medical sciences, 15,455 from natural sciences, 14,841 from social sciences, and 6,054 from others). Obviously, the proportion of medical sciences, who visited the hospital, contributed to about one third of the patients, and was nearly comparable to their own population $(71.2 \%)$. Chronologically, the number of the patients had been raised from 5,168 to 8,793 students per year, and the freshmen had always managed the highest rate.

Along with the crude incidence rate throughout the study period (illustrated in Table 1), the respiratory system, in which acute upper respiratory infection contributed more than $80.0 \%$ (255.6 per 1,000 students), making this the highest incidence rate among these 20 groups. Apparently, medical sciences had the highest amount of incidence rate, among the 4 groups, with 19 out of the 20 health problems. The rate of nervous system complaints, however, was found to be slightly more common in the other groups, in which 80.0 percent of them were migraines or other headache syndromes. The top 8 other problems, included the respiratory system, skin and subcutaneous, injuries, 
Table 1 Crude incidence rate of group-specific health problems, among faculty groups, over the study period

\begin{tabular}{|c|c|c|c|c|c|}
\hline \multirow[b]{2}{*}{ Health problem } & \multicolumn{5}{|c|}{ Crude incidence rate* (per 1,000 students) } \\
\hline & $\begin{array}{l}\text { Medical } \\
\text { sciences }\end{array}$ & $\begin{array}{l}\text { Natural } \\
\text { sciences }\end{array}$ & $\begin{array}{l}\text { Social } \\
\text { sciences }\end{array}$ & Others & $\begin{array}{l}\text { All } \\
\text { students }\end{array}$ \\
\hline Respiratory system & 233.67 & 172.92 & 149.87 & 163.25 & 335.33 \\
\hline Skin and subcutaneous & 122.65 & 71.76 & 78.43 & 73.88 & 162.29 \\
\hline Injuries & 82.40 & 76.16 & 68.61 & 74.73 & 140.03 \\
\hline Musculoskeletal and connective tissue & 91.90 & 71.21 & 67.14 & 68.62 & 139.64 \\
\hline Digestive system & 58.84 & 52.87 & 45.38 & 52.07 & 96.59 \\
\hline Infectious and parasitic diseases & 50.97 & 41.97 & 37.50 & 41.98 & 79.70 \\
\hline Eye and adnexa & 59.16 & 37.48 & 33.29 & 36.51 & 77.36 \\
\hline Genitourinary system & 36.25 & 23.50 & 25.62 & 22.52 & 51.03 \\
\hline External causes of injuries & 30.13 & 25.76 & 24.55 & 28.91 & 49.76 \\
\hline Ear and mastoid process & 23.65 & 15.29 & 13.81 & 16.27 & 31.66 \\
\hline Nervous system & 16.51 & 14.93 & 13.84 & 16.69 & 28.14 \\
\hline Mental and behavior & 19.33 & 11.02 & 12.98 & 9.45 & 25.48 \\
\hline Neoplasms & 12.72 & 8.06 & 11.02 & 6.54 & 20.03 \\
\hline Endocrine, nutrition and metabolism & 11.78 & 7.08 & 10.49 & 10.66 & 18.05 \\
\hline Circulatory system & 8.64 & 4.98 & 6.23 & 4.62 & 11.75 \\
\hline Hematological system & 7.79 & 4.91 & 6.51 & 3.41 & 11.31 \\
\hline Congenital problems, malformations & 2.69 & 1.62 & 1.29 & 1.70 & 3.33 \\
\hline
\end{tabular}

*a cumulative incidence rate of the health problems along 6-year period

musculoskeletal and connective tissue, digestive system, eye and adnexa and the genitourinary system, making up approximately $80.0 \%$ of the overall health problems in the university. Allergic contact dermatitis, acne, and urticarial accounted for half of the skin and subcutaneous problems. About a half of injuries were reported as unspecified regions of bodily injuries: $13.8 \%$, ankle site $11.3 \%$, multiple body regions, $6.4 \%$ and knee site $4.0 \%$. Illustrating among digestive problems; dyspepsia, was the most common problem, accounting for $28.2 \%$. To give attention to eye and adnexa problems, the hordeolum incidence rate contributed for a third of the group, while; conjunctivitis, refractive disorder and lacrimal disorder were less common, in that order. Cystitis, menstrual cycle and female genital organ related pain, abnormal uterine and vaginal bleeding as well as an absent of menstruation played a major role in the genitourinary problems, with each sharing about $15.0 \%$ of these problems.

Apart from this, the external causes commonly accounted by animal related injuries, and transport accidents. Otitis externa, otitis media, and disorder of vestibular organs made up approximately $80.0 \%$ of ear problems. According to mental problems, there were major problems, which accounted for $80.0 \%$ of mental issues, including neuroticism, stress-related disorders, somatoform disorders and mood disorders. Thyroid disorder, obesity, and ovarian dysfunction were problems which contributed to almost $80.0 \%$ in endocrine, nutrition and metabolism aspects. Besides this, hemorrhoids and hypertension played a common role in the circulatory problems. Iron deficiency and other anemia undoubtedly took place in the frequently diagnosed hematological diseases. Lastly, congenital 
malformations of the cardiac septa were most commonly found in a variety of other organ malformations within its group.

Apart from that, health services, including vaccines and other prevention programs, also featured greatly in the hospital's student care. Incidence rate of the services found, as common as 138 per 1,000 students, and has gradually risen for the past 6 years. Also, the students, who encountered these services, prominently were medical sciences students. On the other side, sexual mode transmitted, infectious diseases and pregnancy coupled with pregnancy-related factors were far less than one per 1,000 students, over the 6-year period.

As illustrated in Figure 1, it was a mixed trend among various health problems throughout the year of study. It seemed that the first-year students tended to experience more health problems. Vividly, the red hue predominantly displayed among the medical sciences zone, which ranged from 0.72 to 1.64 . The information mostly indicated a higher incidence rate of overall problems among this groups features. In general, the 4 weightiest problems, including respiratory, skin, musculoskeletal problems and injuries, considerably appeared in the first year. However, the less common diagnosis group's incidence was found to be higher in later years of study. While these patterns, among medical sciences, were remarkable, the rest seemed heterogeneously distributed.

To give a focus on the specificity, influential health problems, undoubtedly, acute upper respiratory tract infections (AURIs), including; acute nasopharyngitis (common cold), acute pharyngitis, and acute tonsillitis, were of the highest incidence rates; making up approximately a quarter of the students during the study time. Again, medical sciences majorly shared a part in almost all problems, excluding transport accidents, which displayed higher rates in the other three. Instead, 'group of others' had the highest transport accident rate, which mostly contributed to motorcycle accident. Dyspepsia was the second most common, with the rate being nearly comparable to those of allergic contact dermatitis (ACD), and acne. Apart from

\section{Health problems}

Respiratory system

Skin and subcutaneous

Injuries

Musculoskeletal and connective tissue

Digestive system

Infectious and parasitic diseases

Eye and adnexa

Genitourinary system

External causes

Ear and mastoid process

Nervous system

Mental and behavior

Neoplasms

Endocrine, nutrition and metabolism

Circulatory system

Hematological system

Congenital abnormalities

\begin{tabular}{|c|c|c|c|c|c|c|c|c|c|c|c|c|c|c|c|}
\hline \multicolumn{4}{|c|}{ Medical sciences } & \multicolumn{4}{|c|}{ Natural sciences } & \multicolumn{4}{|c|}{ Social sciences } & \multicolumn{4}{|c|}{ Others } \\
\hline \multicolumn{4}{|c|}{ Year of study } & \multicolumn{4}{|c|}{ Year of study } & \multicolumn{4}{|c|}{ Year of study } & \multicolumn{4}{|c|}{ Year of study } \\
\hline 1 & 2 & 3 & $\geq 4$ & 1 & 2 & 3 & $\geq 4$ & 1 & 2 & 3 & $\geq 4$ & $\overline{1}$ & 2 & & $\geq 4$ \\
\hline 1.64 & 1.14 & 1.03 & 0.93 & 0.98 & 0.88 & 0.76 & 0.72 & 0.82 & 0.78 & 0.68 & 0.62 & 95 & 0.79 & 0.71 & 0.63 \\
\hline 1.33 & 1.43 & 1.15 & 1. & .75 & 72 & 0.70 & 0.71 & 88 & 0.78 & 76 & & 74 & .75 & 85 & 0.62 \\
\hline 1.21 & 1.08 & 95 & 0.76 & 2 & 90 & 81 & 0 & 00 & 86 & 77 & & 11 & 96 & 75 & 03 \\
\hline 1.48 & 0.90 & 83 & 0.8 & 1.01 & 0.83 & 89 & & 84 & 73 & 75 & & 19 & .89 & 81 & 61 \\
\hline 1.13 & 1.08 & 1.19 & 0.97 & 0.83 & 0.93 & 77 & 0.78 & 0.70 & 0.90 & 76 & 0 . & 88 & 0.83 & 81 & 0.67 \\
\hline 0.93 & 1.27 & 1.11 & 0.93 & 0.84 & 0.84 & 0.81 & 0.91 & 0.76 & 0.82 & 0.82 & 0. & 95 & 0.86 & 0.80 & 0.79 \\
\hline 1.26 & 1.20 & 1.28 & 1.24 & 0.83 & 0.83 & 0.75 & 0.74 & 0.69 & 0.75 & 0.70 & 0.66 & 0.78 & 0.98 & 0.62 & 0.69 \\
\hline 0.82 & 1.17 & 1.43 & 1.19 & 0.82 & 0.65 & 0.83 & 0.70 & 0.80 & 0.83 & 0.70 & 0. & 0.78 & 0.75 & 0.76 & 0.60 \\
\hline 0.82 & 1.15 & 1.21 & 0.84 & 0.73 & 0.95 & 0.87 & 0.76 & 0.85 & 0.94 & 0.75 & 0. & 0 & 1.02 & 0.90 & 0.88 \\
\hline 1.26 & 1.42 & 1.32 & 1.0 & 0.88 & 0.85 & 0.73 & 0. & 0.79 & 0.72 & 0.68 & & 1 & 0.8 & 0.88 & 0. \\
\hline 1.13 & 1.00 & 1.00 & 0.7 & & & 0.77 & & & 0. & & & & 0. & 0.96 & 0. \\
\hline 0.72 & 1.08 & 1.4 & 1.5 & 0.5 & 71 & 0.92 & 0. & & 0.6 & & 1. & & 0.7 & 0.65 & 0. \\
\hline 0.91 & 1.36 & 1.37 & .3 & 3 & 0.71 & 0.76 & 0. & 0.71 & 0.70 & 86 & 0. & 19 & 0.52 & 0.54 & 0. \\
\hline 0.93 & 0.99 & 0.91 & 1.1 & 0.58 & 0.70 & 0.62 & 0. & 0.88 & 0.76 & 0.96 & 1. & 5 & 1.00 & 0.76 & 0.88 \\
\hline 1.06 & 1.16 & 1.52 & 1.15 & 0.65 & 0.68 & 0.86 & 0.60 & 0.88 & 0.74 & 0.94 & 0.93 & 0.55 & 0.55 & 0.54 & 0.93 \\
\hline 0.85 & 0.91 & 1.53 & 1.21 & 0.77 & 0.70 & 0.67 & 0.76 & 1.01 & 0.85 & 0.93 & 1.03 & 0.71 & 0.67 & 0.37 & 0.28 \\
\hline 1.20 & 1.41 & 1.32 & 1.30 & 0.77 & 1.00 & 0.89 & 0.48 & 0.40 & 0.47 & 0.79 & 0.87 & 1.17 & 0.55 & 0.54 & 1.07 \\
\hline
\end{tabular}

Standardized rate ratio (SRR)

Figure 1 Standardized rate ratio of disease-group-specific incidence rate 
that, the incidence rate of mammal bites, and transport accidents were 17.97 and 17.71 per 1,000 students, respectively. Those incidence rates were relatively prominent in the group of others, representing the issue of external causes of injuries. Besides, iron deficiency anemia, in where the rate was comparable to thalassemia and unspecified anemia, found as 2.55 per 1,000 students. In addition, those who had anemia were obviously female students.

According to the information of the disease-groupspecific SRR, Figure 2 illustrated that medical science again played an important role, compared to the university's incidence rate for most diseases, resembling the group trend. The SRR of AURIs in the first year students, and that of acne in the second year, were found to be higher than the population rate (displayed in red hue). Focusing on the remarkable pattern in medical science: AURIs, dyspepsia, ACD, acne and infective diarrhea greatly affected the students in the first year, then dropped afterward. Apart from that, the rests generally displayed a heterogeneous pattern, which was considerably lower than the university's disease incidence rate.

\section{Discussion}

The incidence of diseases of the respiratory system was the highest among the collegians. Adolescents made up the major population of the university during the study period, as the age ranged predominately from 16 to 24 years old. Those who attended the medical sciences discipline group who visited the clinics with health problems, were of the highest proportion (71.0\%). According to the SRR of the incidence, the freshmen remarkably experienced almost all groups of health problems, in the same pattern as medical disciplines, which also presented in most of the problems in red shading. In addition, the freshmen tended to experience more common problems than the others, for instance: respiratory, skin, injuries, and musculoskeletal disorders. On the other hand, this trend seemed to alter in lower incidence groups, such as; hematological and circulatory diseases, in which the SRR were higher in later years of study.

Undoubtedly, AURIs played a greatest role in terms of incidence among diagnoses. From the previous study, which reported a common problem in the primary care and general practice, AURIs also greatly impacted as either the top three or the highest incidence rate. ${ }^{10,11}$ Also, acne and allergic contact dermatitis were found to be more common in the first year of the study year. In the same way, previous reports presented that, skin diseases were the most common issue, and could be of sincere concern to adolescent's. ${ }^{12}$ Additionally, dyspepsia was commonly encountered by the students, as its symptoms

\section{Health problems}

Acute upper respiratory tract infections Dyspepsia

Allergic contact dermatitis

Acne

Bitten or struck by dogs and other mammals

Transport accident

Iron deficiency anemia

\begin{tabular}{|c|c|c|c|c|c|c|c|c|c|c|c|c|c|c|c|}
\hline \multicolumn{4}{|c|}{ Medical sciences } & \multicolumn{4}{|c|}{ Natural sciences } & \multicolumn{4}{|c|}{ Social sciences } & \multicolumn{4}{|c|}{ Others } \\
\hline \multicolumn{4}{|c|}{ Year of study } & \multicolumn{4}{|c|}{ Year of study } & \multicolumn{4}{|c|}{ Year of study } & \multicolumn{4}{|c|}{ Year of study } \\
\hline 1 & 2 & 3 & $\geq 4$ & 1 & 2 & 3 & $\geq 4$ & 1 & 2 & 3 & $\geq 4$ & 1 & 2 & 3 & $\geq 4$ \\
\hline 1.07 & 0.70 & 0.64 & 0.47 & 0.65 & 0.60 & 0.52 & 0.47 & 0.52 & 0.50 & 0.42 & 0.40 & 0.69 & 0.53 & 0.47 & 0.42 \\
\hline 0.84 & 0.67 & 0.78 & 0.61 & 0.49 & 0.57 & 0.44 & 0.49 & 0.52 & 0.55 & 0.50 & 0.45 & 0.64 & 0.51 & 0.55 & 0.44 \\
\hline 0.93 & 0.82 & 0.70 & 0.49 & 0.60 & 0.53 & 0.51 & 0.52 & 0.51 & 0.45 & 0.46 & 0.49 & 0.57 & 0.58 & 0.64 & 0.37 \\
\hline 0.97 & 1.09 & 0.92 & 0.58 & 0.36 & 0.42 & 0.42 & 0.37 & 0.68 & 0.49 & 0.51 & 0.47 & 0.34 & 0.43 & 0.72 & 0.39 \\
\hline 0.56 & 0.88 & 1.03 & 0.57 & 0.37 & 0.55 & 0.55 & 0.41 & 0.46 & 0.56 & 0.58 & 0.53 & 0.53 & 0.47 & 0.82 & 0.68 \\
\hline 0.41 & 0.64 & 0.56 & 0.46 & 0.48 & 0.74 & 0.63 & 0.55 & 0.62 & 0.72 & 0.39 & 0.36 & 0.59 & 0.94 & 0.46 & 0.63 \\
\hline 0.65 & 0.49 & 0.74 & 0.86 & 0.67 & 0.48 & 0.58 & 0.48 & 0.42 & 0.43 & 0.34 & 0.65 & 0.35 & 0.44 & 0.22 & 0.11 \\
\hline
\end{tabular}

0
Standardized rate ratio (SRR)

Figure 2 Standardized rate ratio of disease-specific incidence rate 
include: abdominal pain and stomach pain, these being two of the common presentations in general practice. ${ }^{10,13}$ Furthermore, studies found the disease prevalence as high as $66.0 \%$, and the prevalence of $\mathrm{H}$.pylori as high as $61.1 \%$ among the Thai population. ${ }^{14}$ Apart from dyspepsia, infective diarrhea, which was mostly self-limited in healthy subjects, was also one of the common gastrointestinal problems found in the students; correlating with the previous study. ${ }^{15}$ According to a variety of health problems, both AURIs and dyspepsia SRR illustrated prominently in freshmen.

Freshmen tend to experience almost all common diseases, and reflected a remarkably high rate of overall disease incidence rates throughout the period of the study. There was a study that concluded that: there is a lack of knowledge amoung freshmen in regards to various health aspects, and this might be associated with poor health status, and increased morbidity and mortality. ${ }^{16}$ However, we found that mental and behavioral problems seemed greater in later study years. This information was in contrast to a study in a central regional university, which found a higher prevalence of mental disorders among medical students in the first year of study (the highest rate was in the $2^{\text {nd }}$ year). ${ }^{17}$ In this research, we found the rate of mental problems was considerably lower than in the US $^{4}(2.6$ vs $12.9 \%)$. Various surveys in Asia found that the rate of overall, mental health problems was $4.4-23.6 \%{ }^{18}$ This prevalence variation could be from the difference of health care accessibility, and one's individual perspective. One mental health survey in Thailand found those whom had any mental disorder accessed health care facilities only $11.5 \%$ of the time, while the rate was as high as $56.5 \%$ in the US. ${ }^{18}$

Apart from various groups of diseases, health services, including vaccinations and other programs were one of the common problems for students who visited the hospital, which accounted for approximately $13.8 \%$. The number had also been increasing throughout the study period, as protocols of the student health prevention and promotion program of the hospital had been developed. In different settings, prevention-related services were the most common health issues for US college students that visited hospitals for $(49.0 \%) .{ }^{4}$ Nevertheless, the study also found: Respiratory, dermatologic, infectious, musculoskeletal, injuries and gastrointestinal diseases to be common problems encountered by health centers ${ }^{4}$ (prevalence $36.7,15.5,14.3,11.9,11.9,11.2 \%$, respectively). Apart from common problems, surprisingly, being bitten or attacked by dogs, or other mammals was one of the influential problems found in this study (1.8\%). A survey of tourists, who had travelled to Thailand, revealed that they had been exposed to animals, including: bites and being licked, as the forth placed incidence in Southeast Asia. ${ }^{19}$ In fact, being bitten by dogs was one of the common problems encountered by an emergency department in a university hospital, Thailand (5.3\% of emergency patients), and it was reported that individuals aged 20 years and below were the most common victims. ${ }^{20}$

As adolescents plays a major role in this population, apart from common diseases, health problems found among the students resembled the issues of adolescents, including traffic injury and anemia. The incidence rate of traffic accidents was 17.41 per 1,000, which was almost comparable to provincial and country rates in 2017 (11.12 per 1,000 and 11.84 per 1,000). ${ }^{21}$ This could possibly reflect the contribution of the collegians on traffic-related accidents. Nonetheless, that cannot be negligent as an injury, as this has always been one of the highest expenses of Thailand, costing approximately $2.0-4.0 \%$ of the Gross National Product. ${ }^{8}$ Motorcycle accidents contributed the greatest proportion of this study into traffic accidents, and was found mostly in the group of others; rather than the medical sciences or natural sciences. This is in contrast to the previous publication in northeastern Thailand, that reported the 
highest accident rate in humanities and social sciences. ${ }^{22}$ Anemia, as a part of common cause of morbidity in adolescents, was found to be by 3 major causes: thalassemia, iron deficiency anemia (IDA), and unspecified anemia. There was a paper, that reported that; IDA prevalence in Thailand was approximately $5.0-19.9 \%$, in the general population. ${ }^{23}$

According to a study on the environment, students attending the medical sciences discipline may be prone to exposure to various bloods, and other patient specimens. In addition, increasing awareness among the medical sciences group might increase the rate of visits for many common problems, for example; AURIs and acne, to the health facilities. ${ }^{1}$ Focusing on the accessibility of health care facilities among medical sciences students, the rate of health problems might be slightly aggravated because of the ease of accessibility to the hospital. However, the difference of accessibility might not be the major determinant for the rate of health problems, as there was also the student health center; which most students could equally utilize and contributed to about a half of this study records. The common health problems that were found to be exaggerated among the medical sciences students possibly arised from an increase in their awareness ${ }^{1}$ and disease burden; rather than the context of accessibility.

\section{Strength and limitations}

The exceptional data storing system of Songklanagarind Hospital facilitated the data collection in terms of complete ICD-10 registration for all student visits. Having great cooperation from the Health Promotion Center of the hospital also provided a good detail of student demographic data. However, secondary data analysis, using ICD-10, might limit the precision of diagnosis, as the physician's perspective affected ICD-10 utilization. Also, it could not retrieve further in-depth information from each student record, and it was difficult to find the detail of diseases' related factors or risk factors. Lastly, this study was conducted on 1 universitys, student population, in so that the character of said students, and their contexts are different from other settings. It might have less power to generalize the study outcome to other contexts or universities. We suggest that; future research might include other populations from different universities in order to generalize the results, or work for another analytic statistic, so as to find the significance of the factors among disciplines coupled with other student characteristics.

\section{Conclusion}

The collegians experienced wide ranges of health problems, which predominated in adolescents and adults. Common primary care problems, for example; AURIs, gastrointestinal disorders, skin disorders, anemia and traffic accidents, played a great role in the collegians' health issues. In term of the incidence rates, AURIs, which is one of common primary care problems, contributed to the greatest incidence rate. Traffic accidents contributed a small proportion, however, the rate was considerably higher, once we compared this to provincial and country incidences. Additionally, it can be assumed that the collegians played a part of the role of provincial accidents. Health services provided for the students for the health promotion and prevention programs also contributed greatly in the student visits. Medical sciences students, who might have greater disease awareness, were the number one patients for almost all health issues. In addition, freshmen were also found as a prominent group of students among the various, common health problems. Overall, health problems among the collegians probably varied in the campus due to specific characteristics in each discipline, and differed to the different context in other universities.

\section{Acknowledgement}

The data gathering process was conducted in cooperation with the Division of Health Promotion of 
Songklanagarind Hospital. This work was also supported by the Faculty of Medicine, Prince of Songkla University. In addition, I would like to express my very great appreciation to Mr. Kittisak Choomalee, Ms. Nannapat Pruphetkaew and Mr. Edward McNeil for their constructive, statistical consultation.

\section{Funding sources}

The authors have no support to report.

\section{Conflict of interest}

There are no conflicts of interest in this study.

\section{References}

1. Patrick K, Grace CW, Lovato CY. Health issue for college student. Annu Rev Publ Health 1992;12:253-68.

2. Auerbach RP, Mortier P, Bruffaerts R, Alonso J, Benjet C, Cuijpers $\mathrm{P}$, et al. WHO world mental health surveys international college student project: prevalence and distribution of mental disorders. J Abnorm Psychol 2018;127:623-38.

3. Plummer ML, Baltag V, Strong K, Dick B, Ross DA. Global accelerated action for the health of adolescents (AA-HA!): guidance to support country implementation [monograph on the Internet]. Geneva: World Health Organization; 2017 [cited 2018 Aug 24]. Available from: http://apps.who.int/iris/ bitstream/10665/255415/1/9789241512343-eng.pdf

4. Turner JC, Keller A. College health surveillance network epidemiology and health care utilization of college students at US 4-year universities. J Am Coll Health 2015;63:530-8.

5. Sane J, Ylipaavalniemi P, Turtola L, Niemi T, Laaka V. Traumatic injuries among university students in Finland. J Am Coll Health 1997;46:21-4.

6. Shi H, Yang X, Huang C, Zhou Z, Zhou Q, Chu M. Status and risk factors of unintentional injuries among Chinese undergraduates: a cross-sectional study. BMC Public Health 2011;11: 531.

7. Suparatpinyo S. Psychiatric problem among Khon Kaen University student. J Psychiatr Ass Thailand 1984;34:91-101.

8. Tanaboriboon Y, Satiennam T. Traffic accidents in Thailand. IATSS Research 2005;19:88-100.
9. Powell T, Sammut-Bonnici T. Pareto analysis [monograph on the Internet]. Chichester : Wiley Encyclopedia of Management; 2014 [cited 2018 Sep 20]. Available from: https://www.research gate.net/profile/Tanya_Sammut-Bonnici/publication/ 272353122_Pareto_Analysis/links/59f703bb0f7e9b553 ebd5074/Pareto-Analysis.pdf

10. Britt H, Miller GC, Henderson J, Bayram C, Valenti L, Harrison C, et al. General practice activity in Australia; 2012-13. $\mathrm{BEACH}$ : bettering the evaluation and care of health. Sydney: Sydney University Press; 2013.

11. Wandell P, Carlsson AC, Wettermark B, Lord G, Cars T, Ljunggren G. Most common diseases diagnosed in primary care in Stockholm, Sweden, in 2011. Fam Pract 2013;30: 506-13.

12. Lynfield YL, Laude TA. Common skin problems in adolescents. Int J Adolesc Med Health 1985;1:114-7.

13. Okkes IM, Polderman GO, Fryer GE, Yamada T, Bujak M, Oskam SK, et al. The role of family practice in different health care systems: a comparison of reasons for encounter, diagnoses, and interventions in primary care populations in the Netherlands, Japan, Poland, and the United States. J Fam Pract 2002;51:72.

14. Kachintorn U. Epidemiology, approach and management of functional dyspepsia in Thailand: the management of functional dyspepsia. J Gastroenterol Hepatol 2011;26:32-4.

15. Prajapati SK, Ali AN, Iqbal MZ, Mohanananaidu K, Mei LL, Ningzee C. Health status of students in a private University in Malaysia. Madridge J Pharm Res 2017;1:27-32.

16. Grayeb FAW, Alwawi A, Quaqra D. Health Knowledge among College Freshmen Students in Palestine. Middle-East $\mathrm{J} \mathrm{Sci}$ Res 2016;24:208-13.

17. Ketumarn $P$, Sitdhiraksa N, Sittironnarit G, Limsricharoen $\mathrm{K}$, Pukrittayakamee P, Wannarit K. Psychiatric disorders and personality problems in medical students at Faculty of Medicine, Siriraj Hospital, years 1982-2007. J Psychiatr Assoc Thailand 2012;57:427-38

18. Kittirattanapaiboon P, Tantirangsee N, Chutha W, Tanaree A, Kwansanit P, Assanangkornchai $\mathrm{S}$, et al. Prevalence of mental disorders and mental health problems: Results from Thai national mental health survey 2013. J Ment Health Thai 2017; 25:1-19

19. Piyaphanee W, Kittitrakul C, Lawpoolsri S, Gautret P, Kashino W, Tangkanakul W, et al. Risk of potentially rabid animal exposure 
among foreign travelers in Southeast Asia. PLoS Negl Trop Dis 2012;6:e1852.

20. Bhanganada K, Wilde H, Sakolsatayadorn P, Oonsombat P. Dog-bite injuries at a Bangkok teaching hospital. Acta Tropica 1993;55:249-55.

21. Thai Road Safety Collaboration. Statistical report [monograph on the Internet]. Bangkok: Road Accident Victims Protection; 2017 [cited 2018 Sep 20]. Available from: http://rvpreport. rvpeservice.com/viewrsc. aspx? report=0685\&session $=16$

22. Chumpawadee $U$, Homchampa $P$, Thongkrajai $P$, Suwanimitr A, Chadbunchachai W. Factors related to motorcycle accident risk behavior among university students In northeastern Thailand. Southeast Asian J Trop Med Public Health 2015; 46:17.

23. WHO Global Database On Anemia. Worldwide prevalence of anemia 1993-2005. WHO Global Database on Anaemia 2008 [monograph on the internet]. Geneva: WHO; 2008 [cited on 2018 Aug 24]. Available from: http://apps.who.int/iris/ bitstream/handle/10665/43894/9789241596657_eng.pdf; jsessionid=15B4583B0594C5BA4F3F3A13D07305B4? sequence $=1$

Supplemental document 1 Influential disease cumulative rate among all the university students

\begin{tabular}{|c|c|c|}
\hline Diagnosis & $\begin{array}{l}\text { Crude cumulative } \\
\text { incidence rate } \\
\text { (per } 1,000 \text { students)* }\end{array}$ & $\begin{array}{l}\text { Cumulative } \\
\text { rate }(\%)\end{array}$ \\
\hline Acute nasopharyngitis [common cold] & 108 & 10.8 \\
\hline General examination and investigation of persons without complaint or reported diagnosis & 61 & 16.9 \\
\hline Acute pharyngitis & 51 & 22.0 \\
\hline Examination and encounter for administrative purposes & 38 & 25.8 \\
\hline Other disorders of muscle & 31 & 28.9 \\
\hline Dyspepsia & 28 & 31.7 \\
\hline Acute tonsillitis & 25 & 34.2 \\
\hline Fever of unknown origin & 24 & 36.6 \\
\hline Allergic contact dermatitis & 25 & 39.1 \\
\hline Acne & 22 & 41.3 \\
\hline Diarrhoea and gastro-enteritis of presumed infectious origin & 17 & 43.0 \\
\hline Hordeolum and chalazion & 17 & 44.7 \\
\hline Vasomotor and allergic rhinitis & 18 & 46.5 \\
\hline Other non-infective gastro-enteritis and colitis & 14 & 47.9 \\
\hline Conjunctivitis & 14 & 49.3 \\
\hline Injury of unspecified body region & 13 & 50.6 \\
\hline Dislocation, sprain and strain of joints and ligaments at ankle and foot level & 11 & 51.7 \\
\hline Abdominal and pelvic pain & 11 & 52.8 \\
\hline Urticaria & 10 & 53.8 \\
\hline Other and unspecified vaccines and biological substances & 9 & 54.7 \\
\hline Headache & 9 & 55.6 \\
\hline Acute bronchitis & 8 & 56.4 \\
\hline Gastritis and duodenitis & 8 & 57.2 \\
\hline Bitten or struck by other mammals & 8 & 58.0 \\
\hline Gingivitis and periodontal diseases & 7 & 58.7 \\
\hline Follow-up examination after treatment for conditions other than malignant neoplasms & 8 & 59.5 \\
\hline Embedded and impacted teeth & 7 & 60.2 \\
\hline
\end{tabular}


Supplemental document 1 (continued)

\begin{tabular}{|c|c|c|}
\hline Diagnosis & $\begin{array}{l}\text { Crude cumulative } \\
\text { incidence rate } \\
\text { (per } 1,000 \text { students)* }\end{array}$ & $\begin{array}{l}\text { Cumulative } \\
\text { rate }(\%)\end{array}$ \\
\hline $\begin{array}{l}\text { Other special examinations and investigations of persons without complaint or reported } \\
\text { diagnosis }\end{array}$ & 6 & 60.8 \\
\hline Adverse effects, not elsewhere classified & 7 & 61.5 \\
\hline Acute lymphadenitis & 7 & 62.2 \\
\hline Dental caries & 6 & 62.8 \\
\hline Other dermatitis & 7 & 63.5 \\
\hline Superficial injuries involving multiple body regions & 6 & 64.1 \\
\hline Motorcycle rider injured in other and unspecified transport accidents & 6 & 64.7 \\
\hline Acute sinusitis & 6 & 65.3 \\
\hline Need for immunisation against certain single viral diseases & 6 & 65.9 \\
\hline Dizziness and giddiness & 6 & 66.5 \\
\hline Dengue fever [classical dengue] & 6 & 67.1 \\
\hline Cough & 5 & 67.6 \\
\hline Acute upper respiratory infections of multiple and unspecified sites & 6 & 68.2 \\
\hline Bitten or struck by dog & 6 & 68.8 \\
\hline Dorsalgia & 5 & 69.3 \\
\hline Other soft tissue disorders, not elsewhere classified & 6 & 69.9 \\
\hline Disorders of refraction and accommodation & 5 & 70.4 \\
\hline Gastro-oesophageal reflux disease & 4 & 70.8 \\
\hline Cellulitis & 5 & 71.3 \\
\hline Disorders of lachrymal system & 5 & 71.8 \\
\hline Localised swelling, mass and lump of skin and subcutaneous tissue & 4 & 72.2 \\
\hline Dislocation, sprain and strain of joints and ligaments of knee & 5 & 72.7 \\
\hline Contact with and exposure to communicable diseases & 4 & 73.1 \\
\hline Viral and other specified intestinal infections & 4 & 73.5 \\
\hline Other functional intestinal disorders & 4 & 73.9 \\
\hline Superficial injury of lower leg & 4 & 74.3 \\
\hline Other joint disorders, not elsewhere classified & 3 & 74.6 \\
\hline Dermatophytosis & 4 & 75.0 \\
\hline Viral warts & 4 & 75.4 \\
\hline Asthma & 3 & 75.7 \\
\hline Abnormalities of breathing & 4 & 76.1 \\
\hline Irritant contact dermatitis & 3 & 76.4 \\
\hline Abnormalities of heart beat & 3 & 76.7 \\
\hline Pain in throat and chest & 4 & 77.1 \\
\hline Seborrhoeic dermatitis & 3 & 77.4 \\
\hline Superficial injury of ankle and foot & 3 & 77.7 \\
\hline Enthesopathies of lower limb, excluding foot & 3 & 78.0 \\
\hline Other disorders of conjunctiva & 4 & 78.4 \\
\hline Stomatitis and related lesions & 3 & 78.7 \\
\hline Cutaneous abscess, furuncle and carbuncle & 3 & 79.0 \\
\hline Diseases of pulp and periapical tissues & 2 & 79.2 \\
\hline Special screening examination for infectious and parasitic diseases & 3 & 79.5 \\
\hline Dislocation, sprain and strain of joints and ligaments at wrist and hand level & 3 & 79.8 \\
\hline Superficial injury of wrist and hand & 2 & 80.0 \\
\hline
\end{tabular}

*the value of 6-year period are shown in integer 
Supplemental document 2 Characteristics of the students

\begin{tabular}{lll}
\hline Variables & $\begin{array}{l}\text { Students visited the hospital } \\
\text { with diagnoses } \\
(\mathbf{n = 2 1 , 9 3 9 )}\end{array}$ & $\begin{array}{l}\text { All university students } \\
(\mathbf{n}=\mathbf{4 5 , 0 9 3 )}\end{array}$ \\
\hline $\begin{array}{l}\text { Age in years (mean } \pm \text { S.D.) } \\
\text { Gender }\end{array}$ & $20.9 \pm 2.0$ & $19.0 \pm 2.1$ \\
Male, $\mathrm{n}(\%)$ & $6,579(31.2)$ & $15,628(34.7)$ \\
Female, $\mathrm{n}(\%)$ & $15,360(68.8)$ & $29,465(65.3)$ \\
Discipline group of the students & & $8,743(19.4)$ \\
Medical sciences, $\mathrm{n}(\%)$ & $6,224(27.9)$ & $15,455(34.3)$ \\
Natural sciences, $\mathrm{n}(\%)$ & $6,749(30.2)$ & $14,841(32.9)$ \\
Social sciences, $\mathrm{n}(\%)$ & $6,511(29.1)$ & $6,054(13.4)$ \\
Others, $\mathrm{n}(\%)$ & $2,855(12.8)$ & 16,954 \\
Number of the students per year & & 17,040 \\
2012 & 5,168 & 17,257 \\
2013 & 6,808 & 17,458 \\
2014 & 7,697 & 17,670 \\
2015 & 8,334 & 17,573 \\
2016 & 8,318 & \\
2017 & 8,793 & \\
\hline
\end{tabular}

S.D.=standard deviation

Supplemental document 3 Crude incidence rate of influential specific health problem among faculty groups, over the study period

\begin{tabular}{|c|c|c|c|c|c|}
\hline \multirow{2}{*}{ Health problem } & \multicolumn{5}{|c|}{ Crude incidence rate* (per 1,000 students) } \\
\hline & $\begin{array}{l}\text { Medical } \\
\text { sciences }\end{array}$ & $\begin{array}{l}\text { Natural } \\
\text { sciences }\end{array}$ & $\begin{array}{l}\text { Social } \\
\text { sciences }\end{array}$ & Others & $\begin{array}{l}\text { All } \\
\text { students }\end{array}$ \\
\hline Acute upper respiratory tract infections & 170.92 & 143.22 & 118.75 & 133.76 & 255.63 \\
\hline Dyspepsia & 26.54 & 27.93 & 19.30 & 20.25 & 37.99 \\
\hline Allergic contact dermatitis & 23.20 & 18.32 & 16.17 & 18.19 & 33.91 \\
\hline Acne & 24.06 & 11.48 & 15.68 & 13.71 & 29.16 \\
\hline Bitten or struck by dogs and other mammals & 12.93 & 8.42 & 9.51 & 11.30 & 17.97 \\
\hline Transport accident & 8.85 & 10.47 & 9.17 & 11.44 & 17.41 \\
\hline Iron deficiency anemia & 1.83 & 1.40 & 1.17 & 0.71 & 2.55 \\
\hline
\end{tabular}

*a cumulative incidence of the health problems along 6-year period 